\title{
Concept Analysis of Technostress in Nursing
}

\section{Alham Abuatiq}

College of Natural Sciences, Department of Nursing, California State University,San Bernardino, CA 92407-2318, United States

\begin{abstract}
The purpose of this article is to present a new formulation of stress caused by technology in the nursing field, formulating a new concept named "Technostress". Concept analysis is reported by using Walker and Avant's concept analysis. Since any concept emerges from observed phenomena; a model cases will be presented to demonstrate how technology use is tied to the perception of technostress, and its possible consequences in the health care system, moreover; this article presents the implications of using the concept of 'Technostress' for future research in the nursing field.
\end{abstract}

\section{Introduction}

Technology is strongly association with the historical, scientific, and social frameworks that are embodied in our lives, culture, politics, work, language, education, and other means of communication. One of the major themes of the nursing science in the future is the field of harnessing advanced technology to serve human needs. We as nurses have to assess and advance our practice in implementing technology within the health care setting. We have to plan, organize, and make decisions relevant to the caring process in the context of implementing the postmodern technology that affects the overall quality of care provided to patients.

The purpose of this paper is to present a new formulation of stress caused by technology, presenting a new concept named "Technostress", we will analyze this concept by using Walker and Avant's [1] concept analysis. Since any concept emerges from observed phenomena; a model cases will be presented to demonstrate how technology use is tied to the perception of technostress, and its possible consequences in the health care system, moreover; we will present the implications of using this concept for future research in the nursing field.

Stress is related to many health factors that the patient may suffer from is the most common nursing diagnosis in the nursing care plan, and the nursing interventions in this postmodern time is mainly performed by using technology, starting from taking the blood pressure to assisting a robot in performing a brain surgery. Furthermore, our nursing education depends on using many types of technology starting from simulation labs and ending with teaching students about monitors and computerized machines which are crucial to use in patients care. Also, the nursing research is directed more to improve the quality and safety of care provided for patients, and technology is considered the key of advanced quality of care in this postmodern time.

\section{Identifying the Uses of Technostress Concept}

To explore the true nature of technostress as a concept, I will present the use of this term in all the available literature focusing on the definition, the theoretical perspective, the philosophical perspective of technostress if any is present. Moreover, I will investigate the uses of this concept in sociology and the professional setting to identify as many positive and negative uses of this concept in the relevant fields that will result in expanding the usefulness of this concept analysis outcomes.

\section{Definition of Technostress from Dictionaries}

The definition of Technostress is present in Oxford English Dictionary [2] as "Informal stress or psychosomatic illness caused by working

\section{Publication History:}

Received: November 09, 2014

Accepted: January 14, 2015

Published: January 16, 2015

\section{Keywords:}

Technostress, Nursing

with computer technology on a daily basis". On the other hand, the online dictionary defined Technostress as a "Feeling of anxiety or mental pressure from overexposure or involvement with technology [3].

"Technostress is the negative psychological link between people and the introduction of new technologies. Whereas ergonomics is the study of how humans react and physically fit with machines in their environment, technostress is, in many ways, the resistance of change that accompanies newly introduced machines to work, home, and leisure situations [3].

\section{Professionals Perspectives Relevant to this Concept}

Professionals perspective of Technostress provide more clear designation of this concept; Craig Brod [4]; a leader in the field of technostress research defined technostress for the first time as "A modern disease of adaptation caused by an inability to cope with the new computer technologies in a healthy manner. It manifests itself in two distinct and related ways: in the struggle to accept computer technology and in the more specialized form of over identification with computer technology" [4].

Shenk \& Collins [5] claim that "In the mid-20th century, the introduction of computers, television, satellites, and Internet have created a condition of hyper-production and hyper-distribution that has surpassed human processing ability, leaving us with a permanent processing deficit".

Weil \& Rosen [6] are techno therapists who published a book named “Technostress: Coping with technology@work@home@play", in this book; the authors describe their sixteen years of research into the psychology of technology to show exactly how technology affects our bodies and minds, and the impact it has on our lives at home, at work, and at play. Also they defined Technostress as "Any negative impact on attitudes, thoughts, behaviors, or body physiology that is caused either directly or indirectly by technology" [6] but their definition of technostress considered the negative impact of technostress only, so could the technostress have positive impact on attitudes, thoughts, behaviors or body physiology?

"Corresponding Author: Dr. Alham Abuatiq, College of Natural Sciences, Department of Nursing, California State University,San Bernardino, CA 924072318, United States; E-mail: aabuatiq@csusb.edu

Citation: Abuatiq A (2015) Concept Analysis of Technostress in Nursing. Int $J$ Nurs Clin Pract 2: 110. doi: http://dx.doi.org/10.15344/2394-4978/2015/110

Copyright: (c) 2015 Abuatiq. This is an open-access article distributed under the terms of the Creative Commons Attribution License, which permits unrestricted use, distribution, and reproduction in any medium, provided the original author and source are credited. 


\section{Theoretical Perspective of Technostress}

There are several theoretical positions advised for understanding stress and stress-related disorders, but none embedded the technostress concept in its context. Brantley and Thomason [7] categorized them into three groups: response theories, stimulus theories, and interaction theories. Historically, both Walter Cannon and Hans Selye provided the foundation for the current interest in the physiological effects of stress on our body.

Lazarus and Folkman's [8] Theory of Stress and Coping is the most relevant theory to the concept technostress, according to them; "stress is a relationship between an individual and the environment in which the individual interacts. The decision on whether or not the situation is stressful depends upon the cognitive appraisal of the individual Furthermore, the extent to which a harmful or potentially harmful encounter between the person and environment is stressful depends on the meaning and significance of that encounter, which in turn is based on the personal agendas and coping resources the person brings to it" [1].

\section{Use of Technostress Concept in Sociology}

Nowadays, the humans' social behavior is greatly affected by the use of technology in communication, industry and could not be separated from any work field. In the same time technology made the humanitarian interaction less frequent, thus broadening the stress causes.

It will be helpful to consider the mother concept of technostress which is "Stress". According to Pearlin [9] the sociological inquiry of stress focus on how the causes of stress and the outcomes of stress vary across subgroups in the population, and the social condition of individuals can determine different stress outcomes.

Kupersmith [10] suggested that individuals from mental models of how to operate the new technology and how different actions produce different effects. Once the technology has changed, as in the introduction of new technology, these mental models no longer work. When the new technology is more complex, the individual has a difficult time forming new models which can result in the development of technostress.

\section{The Defining Attributes of the Technostress Concept}

According to Brod [4] "Technostress has a negative impact on human performance by shifting a person's work-congruent stress to an internal state of distress. This results in a reduced-ability to process information accurately, a slowing of the response time to computergenerated demands, and an interruption of normal work patterns. Technostress often begins as reduced performance which limits the usefulness of the technology".

As stated by Brod [4] "The primary symptom of technostress is anxiety, an individual can exhibit this anxiety in many ways such as nightmares, headaches, resistance to learning about the new technology, and outright rejection of the technology". Furthermore, Brod suggested that there are several important variables that affect the probability of developing technostress like the age of the user, past experience with technology, perceived control over new tasks, and organizational climate.

From my view of point, the defining attributes of the concept of Technostress include: unpleasant experiences originating from the use of technology in our daily lives, the individual experience's psychological disturbances manifested by anxiety, temporary confusion as to how to use the technology, fear of being rushed or dehumanized by the technology that could develop from being novice in using technology to perform the required task. Also the individual may experience physical disturbances that could result from using the technology like repetitive spasms or strain injuries, carpel tunnel syndrome, eyes problems, headache, obesity or back problems resulting from poor machine design or staying for long hours using the computerized technology.

\section{Model Cases of Technostress in Nursing}

A model case should include all attributes of the concept and should be a paradigmatic example. It also illustrates the attributes of the concept [1]. The following example presents a model case for the concept of Technostress.

First Model Case: Mr. A, is a 33 years old man who was admitted to the intensive care unit after road traffic accident, his son was with him in the car and did not survive. Mr. M was in deep coma and have Cervical spine injury and stabilized in one of the rolling electronic ICU beds. Sally is a 55years old nurse was assigned to Mr. M.

At $9 \mathrm{pm}$ the patient's cardiac monitor started to give alarm for VF, the nurse checked Mr. M pulse and he had a weak pulse, the ICU physician and another nurse brought the ER-cart. the physician confirmed that Mr. M still have weak pulse, the rolling bed was setting Mr. M in prone position and still rolling, Sally; the nurse was staring on the electronic bed control screen and was pushing buttons to set the bed in supine position, and the bed started to give alarms.

One of the young nurses noticed that Sally was confused and not comfortable in using this electronic bed, so she offered to help and it took a while to return the patient's bed to supine position. Meanwhile, another nurse was attaching Mr. M to the defiblarator electrodes then the defiblirator screen was showing bradycardia ECG rhythm, while the bedside cardiac monitor was still giving alarm for VF rhythm. The ICU CPR team was shocked, confused and fear to manage the patient incorrectly due to the contradictory analysis, the physician said "those cardiac monitors are causing noise and headache "and he decided to go with the bradycardiac rhythm since Mr. M was having a weak pulse and atropine was given to the patient and retrieved to normal sinus rhythm.

The patient's wife was observing all what was happening, the nurse had to change Mr. M cardiac monitor to the defiblirator monitor and keep it charged with electricity all the time. After Mr. M was stabilized, Sally preferred to keep Mr. M in supine bed position so she will not have troubles in setting the bed again. Then she went to document nursing notes using the computerized charting system, while she was typing on the keyboard her hands were shivering, she was gazing in the computer screen and sweating, and said to the other nurse "I have headache from this computerized charting system, it never logs me in", the other nurse replied "You seem confused and anxious whenever you use computerized technology? Sally replied "Yes, I do not know what is happing with me, whenever it comes to computer screens or keyboards I feel headache and confused, I wish we can use papers instead!", in the same time the patient's wife phone did not stop ringing and the nurse heard her say "they took long time to roll the bed back to the right position while the alarms were all on, I will sue this hospital". 
Analysis: this Model case illustrated all the critical attributes of Technostress concept in which the Nurse Sally suffered from, she showed her technostress as an unpleasant and distressful, confusing, high anxiety experience, and she verbally and non-verbally expressed having physical symptoms like headache, sweating and shivering while using the computerized screen and keyboard. Also the CPR team was shocked and confused and feared from making incorrect interventions.

Second Model Case: Mr. L, 44 years old married and live with his wife and 3 children's, J.J one of his kids was watching the TV in loud, the mother lowered the sound and asked her son to finish his homework but he was gazing on the TV screen and all his senses was attached to the TV screen, his older brother grasped the TV remount from his hand and changed the channel. J.J asked his brother to turn back to the show channel but no reply, and then JJ started to scream forcing his brother to go back to the show channel. Their mother said "this TV is source of headache" then she turned off the TV and forced both of them to go back to their room .J.J had high level of anxiety since he missed his favorite TV show.

Third Model Case: Mrs. K is 48 years old Phd student, she had her oral defense. One of her committee professors preferred to attend her oral defense via online broadcast. Mrs. K was ready and fully prepared for her presentation. She brought her own laptop, and saved the presentation in a brand new flash drive. She saved her presentation with password protection. Her lap top did not restart, and she decided to use the computer in the lecture hall and asked the help of one of the computer specialists to set up the computer saying "Can you help me start the computer, I have headache and back pain from using computers", And her flash drive opened the presentation file which also included internet connection. The internet was working well. She entered the password but the computer did not give her access, she said "I think I'm anxious and confused, oh.. my hand hurts me from the keyboard" she repeated entering the password until the file opened. And when she turned on the microphone it produced 'zzzzzz" echo sound and was not able to use the microphone. She said "I wish if those kind of technology does not present".

Analysis of the second and third Model cases: in both cases, the individuals expressed verbally and non verbally that the use of computerized technology affected their psychological integrity causing anxiety, confusion, irritability and feelings of fear and resistance to learn or use the new technology, and outright rejection of the technology. Also they expressed some physical negative effects due to the use of such technology that caused headache, back pain or hands spasm and noise.

\section{Additional Cases}

Border line case: Jim, 12 years old boy and spend most of his time playing video games, he rarely go and play with his age group kids, his biggest fun is when he wins a video game. His mother noticed that he is gaining more weight recently, He says "I could not imagine my life without computers and video games, and I gained some weight because I'm eating all the time, but video games are my passion, and I love to communicate with my sister online while she is only upstairs!".

Analysis of border line case: This example dose not present all the critical attributes of the technostress concept, since Jim did not verbally express any psychological or physical attributes relevant to technostress and more investigation is needed to rule out the causes of weight gain.
Related case : M. Mill have invested in the computer industry field and have $40 \%$ of the world stocks in his name, in 2008 during the economical crisis, customers withdrew from buying his brand of the computers and he lost a lot in his investments. His wife said "Since the time he lost his investments, he is always in his office just setting anxious in front of the computer, worried and fear something worse could happen, also he rarely comes back home or have time with the kids" he told her many times that he "have severe headache and he lost lots of weight within the last month".

Analysis of the related case: This is a pure stress case and Mr. Mill is having psychological anxiety that affected his physical appearance. The loss of his investments affected his interaction with his family, his wife mentioned that he is totally changed since the time he lost his investments and his anxiety and physical symptoms are not due to the direct use of the computerized technology.

Contrary case: Nurse. L, he used to work in one of the best magnet hospitals that use high technology to provide nursing care for patients. He volunteered to work in Haiti after the earthquake, due to the basic infrastructure in Haiti, he was forced to use the primary non technology equipments due to lack of electricity, also his font in the nursing notes were hard to read from papers since he used to document using the computerized charting for several years in his work, he found it difficult to adapt to the health care services in Hiati, and since he was volunteering he decided to go back to his work in the magnet hospital in which he feels most effective in doing his work with less stress.

Analysis of Contrary case: the defining attributes of technostress are absent in this example, it represents the concept of poor adaptation due to the dramatic change in the environment.

\section{Antecedents and Consequences of the Technostress Concept}

Antecedents are the incidents that happen before the existing concept [11] environmental, personal and technological aspects act as antecedents related to the concept of technostress.

Antecedents: The presence of computerized technology in which the individual should interact in order to perform tasks. This interaction may be audiovisual by observing the machine's screen or Physical by clicking on the screen or keyboard, or even having the technology as part of the body for example patients with permanent pace maker or patients with robot whole hand or leg. Computer technology include computers, phones, ipods, ventilators, CPAP, MRI, CT scan machines, electronic beds, infusion pumps, or any new machine that need to be charged with electricity could be considered a part of technology. The person attached to those machines or the person who is controlling the setting of those machines have different levels of proficiency in using such technology, since their experiences and age group affects their interaction with the computerized technology.

Consequences: Consequences are incidents that happen as a result of the concept [11]. The consequences of techno stress are related to a negative experience or interaction and the individual's own interpretation of the meaning of technostress. Technostress reactions include any psychological, mental and physical negative effects on the human being. And those reactions could be verbally and none verbally expressed by the individual. Using the keyboard and screen may cause physical disturbances like headache, back ache, impaired vision, and auditory distraction, anxiety, confusion and being uncomfortable psychologically and physically when using the computerized technology. 


\section{Definition of Empirical Referents for the Defining Attributes}

This is the final step in concept analysis, from the analysis of Technostress, the critical attributes may be abstract; thus empirical references present how these attributes exist in reality. Thus, analysis of the concept can be used to develop an instrument for investigating this concept. The empirical referents for technostress concept include: the individual own verbalization are the most reliable Technostress indicator, but it may be not explicit for every person since this concept is new, but mainly the individual will express or suffer from anxiety that emerge due to the use of technological machines. Fear from clicking wrong setting or orders to the computerized technology machines. Headache due to interacting with computerized machines to perform tasks of daily living. Uncomfortable feeling due to the use of keyboard not a pen, or being forced to trust a machine to support life. Worry about losing the passwords or forgetting it, which is needed to open file of valuable information's. being physically uncomfortable and suffering from headache or spasms due to the use of computerized machines to perform tasks of daily living.

\section{Implications for Future Research}

The study of this concept in the nursing field will help in investigating the technostress phenomena starting by a qualitative survey to gain some understanding for how nurses preview this concept, interviewing nurses and patients and asking them about their own perception regarding technostress and its attributes and how it could affect the outcomes of patient care. Future research is encouraged to focus on the effects of using technology in health care environment.

\section{Conclusion}

Technostress as a concept is studied in the technology field mainly, hospitals development depends on the use of technologies in patients care, nursing is the primary care given to those patients and the use of computerized technology affects all aspects of the nursing practice in the hospital setting.

The main goal this concept analysis is to examine the concept of Technostres from the available literature by following Walker \& Avant's [1] concept analysis, and illuminate the available theoretical, philosophical and technotherapists perspectives. a model case will be presented to demonstrate how technology and stress caused by it is tied to the perception of technostress and its possible consequences in the health care system. This analysis will guide the future research and investigate the use of this phenomenon in the nursing field.

\section{Competing Interests}

The author declare that she has no competing interests.

\section{References}

1. Walker L, Avant K (2005) Strategies for theory Costruction in Nursing.

2. Technostress (2010) In Wikipedia, The Free Encyclopedia.

3. Technostress (2010) Dictionary.com's 21st Century Lexicon.

4. Brod C (1984) Technostress: the human cost of the computer revolution. Reading, MA: Addison-Wesley.

5. Shenk D, Collins H (1997) Data Smog: Surviving the Information Glut.1st edition New York.

6. Weil MM, Rosen LD (1997) Technostress: Coping with Technology @Work @Home @Play, New York: Wiley and Sons.

Int J Nurs Clin Pract

ISSN: 2394-4978
7. Brantley PJ, Thomason BT (1995) Stress and stress management. In A. J. Goreczny (Ed.), Handbook of Health and Rehabilitation Psychology (pp. 275-289). New York: Plenum Press.

8. Gruen RJ, Folkman S, Lazarus RS (1988) Centrality and individual differences in the meaning of daily hassles. J Pers 56: 743-762.

9. Pearlin, Leonard I (1999) The Stress Process Revisited. In: Aneshensel, Carol S, Phelan Jo C (eds) Handbook of Sociology of Mental Health. Kluwer Academic/Plenum Publishers.

10. Kupersmith J (1992) Library Technostress Survey Results.

11. Technostress (1989) In Oxford English Dictionary. 